\title{
A High-Volume Cryosampler and Sample Purification System for Bromine Isotope Studies of Methyl Bromide*
}

\author{
BRETT F. THORNTON \\ Department of Applied Environmental Science, Department of Geological Sciences, and Bolin Centre for Climate Research, \\ Stockholm University, Stockholm, Sweden \\ AXel Horst, DANIEl CARrizo, ${ }^{+}$AND Henry HolmSTrand \\ Department of Applied Environmental Science, and Bolin Centre for Climate Research, Stockholm University, Stockholm, Sweden
}

PER ANDERSSON

Laboratory for Isotope Geology, Swedish Museum of Natural History, Stockholm, Sweden

PATRICK M. CRILL

Department of Geological Sciences, and Bolin Centre for Climate Research, Stockholm University, Stockholm, Sweden

ÖRJAN GUSTAFSSON

Department of Applied Environmental Science, and Bolin Centre for Climate Research, Stockholm

University, Stockholm, Sweden

(Manuscript received 22 October 2012, in final form 7 April 2013)

\begin{abstract}
A system was developed for collecting from the ambient atmosphere the methyl halides $\mathrm{CH}_{3} \mathrm{Cl}$ and $\mathrm{CH}_{3} \mathrm{Br}$ in quantities sufficient for chlorine and bromine isotope analysis. The construction and operation of the novel cryogenic collection system (cryosampler) and sample purification system developed for this task are described. This study demonstrates the capability of the cryosampler by quantifying the $\mathrm{CH}_{3} \mathrm{Cl}$ and $\mathrm{CH}_{3} \mathrm{Br}$ collected from atmospheric samples and the nonfractionating bromine isotope fingerprint of $\mathrm{CH}_{3} \mathrm{Br}$ from synthetic air samples of controlled composition. An optimized cryosampler operation time of $4 \mathrm{~h}$ at a flow rate of $15 \mathrm{~L} \mathrm{~min}^{-1}$ is applied to yield the nearly $40 \mathrm{ng}$ required for subsequent $\delta^{81} \mathrm{Br}-\mathrm{CH}_{3} \mathrm{Br}$ analyses. The sample purification system is designed around a packed column gas chromatography-quadropole-mass spectrometry (GCqMS) system with three additional cryotraps and backflushing capacity. The system's suitability was tested by observing both the mass recovery and the lack of $\Delta^{81} \mathrm{Br}$ isotope fractionation induced during sample purification under varying flow rates and loading scenarios. To demonstrate that the entire system samples and dependably delivers $\mathrm{CH}_{3} \mathrm{Br}$ to the isotope analysis system without inducing isotope fractionation, diluted synthetic air mixtures prepared from standard gases were processed through the entire system, yielding a $\Delta^{81} \mathrm{Br}_{-} \mathrm{CH}_{3} \mathrm{Br}$ of $+0.03 \% \pm 0.10 \%$ relative to their starting composition. Finally, the combined cryosampler-purification and analysis system was applied to demonstrate the first-ever $\delta^{81} \mathrm{Br}-\mathrm{CH}_{3} \mathrm{Br}$ in the ambient atmosphere with two samples collected in the autumn of 2011 , yielding $-0.08 \% \pm 0.43 \%$ and $+1.75 \% \pm 0.13 \%$ o versus standard mean ocean bromide for samples collected at a suburban Stockholm, Sweden, site.
\end{abstract}

* Supplemental information related to this paper is available at the Journals Online website: http://dx.doi.org/10.1175/JTECH-D-12-00228.s1.

${ }^{+}$Current affiliation: Department of Analytical Chemistry, University of Zaragoza, Zaragoza, Spain.

Corresponding author address: Brett F. Thornton, Dept. of Geological Sciences, Stockholm University, Svante Arrhenius väg 8, SE10691 Stockholm, Sweden.

E-mail: brett.thornton@geo.su.se

DOI: 10.1175/JTECH-D-12-00228.1 


\section{Introduction}

Methyl bromide and methyl chloride $\left(\mathrm{CH}_{3} \mathrm{Br}\right.$ and $\mathrm{CH}_{3} \mathrm{Cl}$, respectively) are the largest natural sources of chlorine (Kurylo et al. 1998) and bromine (e.g., Sinnhuber et al. 2005) to the stratosphere. Since it is a controlled compound under the Copenhagen Amendment to the Montreal Protocol (UNEP 2012), the human contribution to atmospheric $\mathrm{CH}_{3} \mathrm{Br}$ is presumably now decreasing (Montzka et al. 2011; Yvon-Lewis et al. 2009). With dominant losses occurring in the troposphere via reaction with the hydroxyl $(\mathrm{OH})$ radical, both gases have relatively short atmospheric lifetimes- $-0.8 \mathrm{yr}$ for $\mathrm{CH}_{3} \mathrm{Br}$ and $1.0 \mathrm{yr}$ for $\mathrm{CH}_{3} \mathrm{Cl}$. Nevertheless, a fraction of each of these gases does reach the stratosphere (Salawitch et al. 2005), where $\mathrm{CH}_{3} \mathrm{Br}$ is currently responsible for about $15 \%$ of the halogen-induced ozone loss and $\mathrm{CH}_{3} \mathrm{Cl}$ is responsible for about 13\% (Butler 2000). Although the concentration of the methyl halides $\left(\mathrm{CH}_{3} \mathrm{X}\right)$ in the atmosphere is now well known, numerous natural sources and sinks have been identified, some quite recently—for example, fungi (Harper 1985), macroalgae (Laturnus 2001; Laturnus et al. 1998; Manley and Dastoor 1987), peatlands (Khan et al. 2012; Varner et al. 1999), rice paddies (Khan et al. 2011; Redeker et al. 2002), salt marshes (Rhew et al. 2000; Rhew and Mazéas 2010), oceans (Hu et al. 2010; King et al. 2000; Lu et al. 2010; Singh et al. 1983), tropical rain forests (Saito et al. 2008), tundra (Rhew et al. 2007; Teh et al. 2009), fires (Andreae et al. 1996), cattle (Williams et al. 1999), and ants (Mead et al. 2008). Thus, many questions and uncertainties in the global budgets of these gases remain (e.g., Butler 2000; Montzka et al. 2011; Simmonds et al. 2004; Yvon-Lewis et al. 2009).

The importance of understanding the sources and sinks of methyl halides will likely grow, as they are expected to become the dominant sources of inorganic chlorine and bromine to the stratosphere in the second half of the twenty-first century, overshadowing the waning amounts of anthropogenic chlorofluorocarbons and halons (Law et al. 2007). It has been speculated that changes in atmospheric circulation may transport more short-lived source gases of $\mathrm{Cl}$ (Law et al. 2007) and $\mathrm{Br}$ (Dessens et al. 2009) — such as the methyl halides—-to the upper troposphere-lowermost stratosphere (UTLS). This may impact the halogen burden in the UTLS, where ozone changes may have large radiative forcing effects. Both methyl halides themselves (e.g., Schauffler et al. 1993, 2003) and the "active" inorganic halogen species formed from the breakdown of the methyl halides have been observed in situ in the UTLS region, from the Arctic (Thornton et al. 2003) to the midlatitudes (Borrmann et al. 1997; Thornton et al. 2007) and tropics (von Hobe et al. 2011). Thus, understanding the sources and sinks of methyl halides in the atmosphere, and how they might change in the future, is critical for predictions of both stratospheric ozone change and radiative forcing and climate change.

One promising technique for determining sources and sinks of gases is the use of stable isotope systematics. Changes in the ratios of naturally occurring isotopes in a sample occur via biological, chemical, transport, and temperature processes (Keppler et al. 2004); these are generally referred to as kinetic isotope effects (KIE) and occur because of differences in chemical bond strengths between isotopes at reactive positions (Hoefs 2009).

Previous work has successfully shown fractionations in the bromine isotope system in organobromine substances (Carrizo et al. 2011; Holmstrand et al. 2010; Sylva et al. 2007), and in geologic systems (e.g., Kaufmann et al. 1984; Shouakar-Stash et al. 2007). Further, it is known that enzymatic dehalogenation reactions impart a particular chlorine KIE on various organochlorine compounds (e.g., Numata et al. 2002; Paneth 2003). For atmospheric systems, isotope studies have been largely confined to a few elements, especially $\mathrm{C}$ and $\mathrm{H}$ (e.g., Bill et al. 2002; Brenninkmeijer et al. 2003; Keppler et al. 2004, 2005; McCauley et al. 1999; Miller et al. 2001; Saito and Yokouchi 2008). The use of multiple isotope systems might allow the source or sources of a particular sample of, for instance, methyl bromide to be ascertained with greater certainty. The $\mathrm{Cl}$ and $\mathrm{Br}$ isotope systems in the atmosphere are lightly studied. Likely reasons for this include the trace levels at which these compounds are present in the background atmosphere, possible small KIEs for the $\mathrm{Cl}$ and $\mathrm{Br}$ isotope systems as compared with lighter elements, and the poor sensitivity of previously available halogen isotope analytical techniques. Hence, a method for obtaining the halogen isotopic signatures of methyl halides in the atmosphere may lead to more reliable global budgets.

The primary goal of the halocarbon volatile cryotrap (HAVOC) system and the subsequent sample purification system is to procure $\mathrm{CH}_{3} \mathrm{Br}$ from the ambient atmosphere in sufficient purity and quantity and without method-induced isotope fractionation so as to allow high-precision $\mathrm{Br}$ isotope analysis; this paper describes reaching these goals. A secondary goal is trapping sufficient $\mathrm{CH}_{3} \mathrm{Cl}$ for $\mathrm{Cl}$ isotope analysis. Our current analytical method for bromine isotopes [gas chromatography hyphenated with inductively coupled plasma multicollector mass spectrometry (GC-ICP-mcMS)] has a limit of quantification (LOQ) of $40 \mathrm{ng}$ of $\mathrm{Br}$ (Horst et al. 2011) for analysis of $\mathrm{Br}$ isotopes, which is the lowest amount of Br that still could be determined with a precision of better than $0.1 \%$. This high precision is necessary to resolve the relatively small fractionation effects of $3 \%{ }^{-}-4 \%$ for $\mathrm{Br}$ 
TABLE 1. Sample requirements for halogen isotope analyses of methyl halides. The asterisk denotes approximate nanograms per cubic meter at STP. Here, GC-qMS is gas chromatograph + quadropole mass spectrometer, GC-ICP-MC-MS is gas chromatograph + inductively coupled plasma torch + multicollector mass spectrometer, and GC-IRMS is gas chromatograph + isotope ratio mass spectrometer.

\begin{tabular}{lll}
\hline \hline & \multicolumn{1}{c}{$\mathrm{CH}_{3} \mathrm{Cl}$} & \multicolumn{1}{c}{$\mathrm{CH}_{3} \mathrm{Br}$} \\
\hline $\begin{array}{l}\text { Approximate 2012 tropospheric concentration* } \\
\begin{array}{l}\text { Methyl halide mass requirement for halogen } \\
\text { isotopic analyses }\end{array}\end{array}$ & $\begin{array}{l}550 \mathrm{ppt} \text { or 1300 } \mathrm{ng} \mathrm{m}^{-3} \\
<40 \mathrm{ng} \text { (GCqMS; Aeppli et al. 2013) }\end{array}$ & $\begin{array}{l}\text { 8 ppt or 31 } \mathrm{ng} \mathrm{m}^{-3} \\
40 \mathrm{ng} \text { (GC-ICP-mcMS; Horst et al. 2011) }\end{array}$ \\
$\begin{array}{l}\text { Methyl halide mass requirement for carbon } \\
\text { isotopic analyses }\left(\delta^{13} \mathrm{C}\right)\end{array}$ & $1 \mathrm{ng}$ (GC-IRMS; Rudolph et al. 1997) & 2 ng (GC-IRMS; Bahlmann et al. 2011) \\
$\begin{array}{l}\text { Whole air sample size for one sample } \\
(+50 \% \text { margin) }\end{array}$ & $\sim 20 \mathrm{~L}(\mathrm{GCqMS})$ & 2000 L (GC-ICP-mcMS) \\
\hline
\end{tabular}

(e.g., Shouakar Stash et al. 2007). In this study, we are aiming mainly for $\delta^{81} \mathrm{Br}$ measurements of $\mathrm{CH}_{3} \mathrm{Br}$. Given that $\mathrm{CH}_{3} \mathrm{Cl}$ is present in the atmosphere at approximately 450-600 pptv and that $\mathrm{CH}_{3} \mathrm{Br}$ is present at approximately 6-8 pptv, $\mathrm{Cl}$ isotope studies using the recently developed gas chromatography single-quadropole mass spectrometry systems (GCqMS) method (Aeppli et al. 2010) may be accomplished with far lower amounts of atmospheric sample-LOQ $<40 \mathrm{ng}$ of $\mathrm{Cl}$ (Aeppli et al. 2013) - than are trapped by the cryosampler while collecting samples for $\mathrm{CH}_{3} \mathrm{Br}$ analysis. This means that samples for potential $\mathrm{Cl}$ isotope studies can be captured "alongside" samples for $\mathrm{Br}$ analysis. The cryosampling system described in this paper is primarily intended for use with the $\mathrm{Br}$ isotope system, which consists of two stable isotopes: ${ }^{79} \mathrm{Br}(50.69 \%)$ and ${ }^{81} \mathrm{Br}(49.31 \%)$. The system may also be useful for the $\mathrm{Cl}$ isotope system $-{ }^{35} \mathrm{Cl}(75.77 \%)$ and ${ }^{37} \mathrm{Cl}(24.23 \%)$, and we will make some mention of preliminary tests for $\mathrm{CH}_{3} \mathrm{Cl}$.

\section{Cryosampler and sample purification systems}

Cryosampling systems have been built using either cryogen-based cooling — for example, Huff et al. (1997) or as refrigerant-based systems-for example, Sive et al. (2005). Generally, cryogen-based systems are able to collect samples more rapidly, at the expense of higher cryogen use. A key difficulty in stable isotopic analysis of atmospheric trace gases is the preconcentration of a sufficient quantity of these gases for isotopic analysis, and their separation from the complex matrix of atmospheric air. The target compounds of our cryosampler, $\mathrm{CH}_{3} \mathrm{Br}$ and $\mathrm{CH}_{3} \mathrm{Cl}$, have freezing/boiling points of $-94^{\circ} / 3.6^{\circ} \mathrm{C}$ and $-98^{\circ} /-24^{\circ} \mathrm{C}$, respectively. $\mathrm{CH}_{3} \mathrm{Br}$ is especially challenging to collect in sufficient quantity, given its present background tropospheric abundance of approximately 8 pptv. The system described herein overcomes this challenge of sampling the remote atmosphere $\mathrm{CH}_{3} \mathrm{Br}$ with a large-volume air sampling system that cryotraps target analytes in quantities needed for halogen isotope analyses (Table 1) while preserving isotopic integrity.

\section{a. HAVOC high-volume cryosampler construction}

The cryogenic sampling system consists of several components (Fig. 1). Details of the primary cryotrap are shown in the supplemental material (Fig. S1). Important parameters are listed in Table 2. Components include a primary drying unit, a secondary drying unit, the cryotrap itself, a carbon dioxide removal unit, a heating unit, sample transport and storage cylinders, a pump to move air through the system for sampling and purging, and a helium tank for physically flushing samples into the storage cylinders.

The entire HAVOC cryotrap system is contained within a wooden frame that is approximately $1.5 \mathrm{~m}$ high and $80 \mathrm{~cm}$ square, which can split into two pieces for easy transport. In field operation, the sampled atmospheric air is obtained from a short mast that is approximately $4 \mathrm{~m}$ high, pulling air through a $1 / 4-$ in. $(1$ in. $=25.4 \mathrm{~mm})$ tube to the sampler at a height of about $0.5 \mathrm{~m}$ above surface level. Ambient air temperature and humidity are monitored. Type-N thermocouples (Pentronic, Gunnebo, Sweden) are used throughout the system, connected to a universal serial bus (USB) thermocouple datalogger controlled from a laptop running the Windows XP operating system (logging software and USB datalogger by Pico Technology, Cambridgeshire, United Kingdom). The pumping of air is provided by a KNF Neuberger (Freiburg, Germany) Series N 145.1.2 AT.18 diaphragm pump, located at the "end" of the airflow path, after the cryotrap. The pump can move over $25 \mathrm{~L} \mathrm{~min}^{-1}$ of air through the assembled system and can achieve an ultimate pressure of $<100 \mathrm{hPa}$ on a closed system. The airflow is throttled down to $\sim 15 \mathrm{~L} \mathrm{~min}^{-1}$ using a needle valve (Swagelok SS-IRS4).

Sample air first encounters the primary drying unit. This is a simple condensation trap, consisting of two 250-mL borosilicate vacuum flasks (Schott, Mainz, Germany) arranged in series and immersed in ice water. Much of the water in the sampled air is removed by this simple step. After passing through a quartz fiber filter that removes most remaining particulates, sample air next 


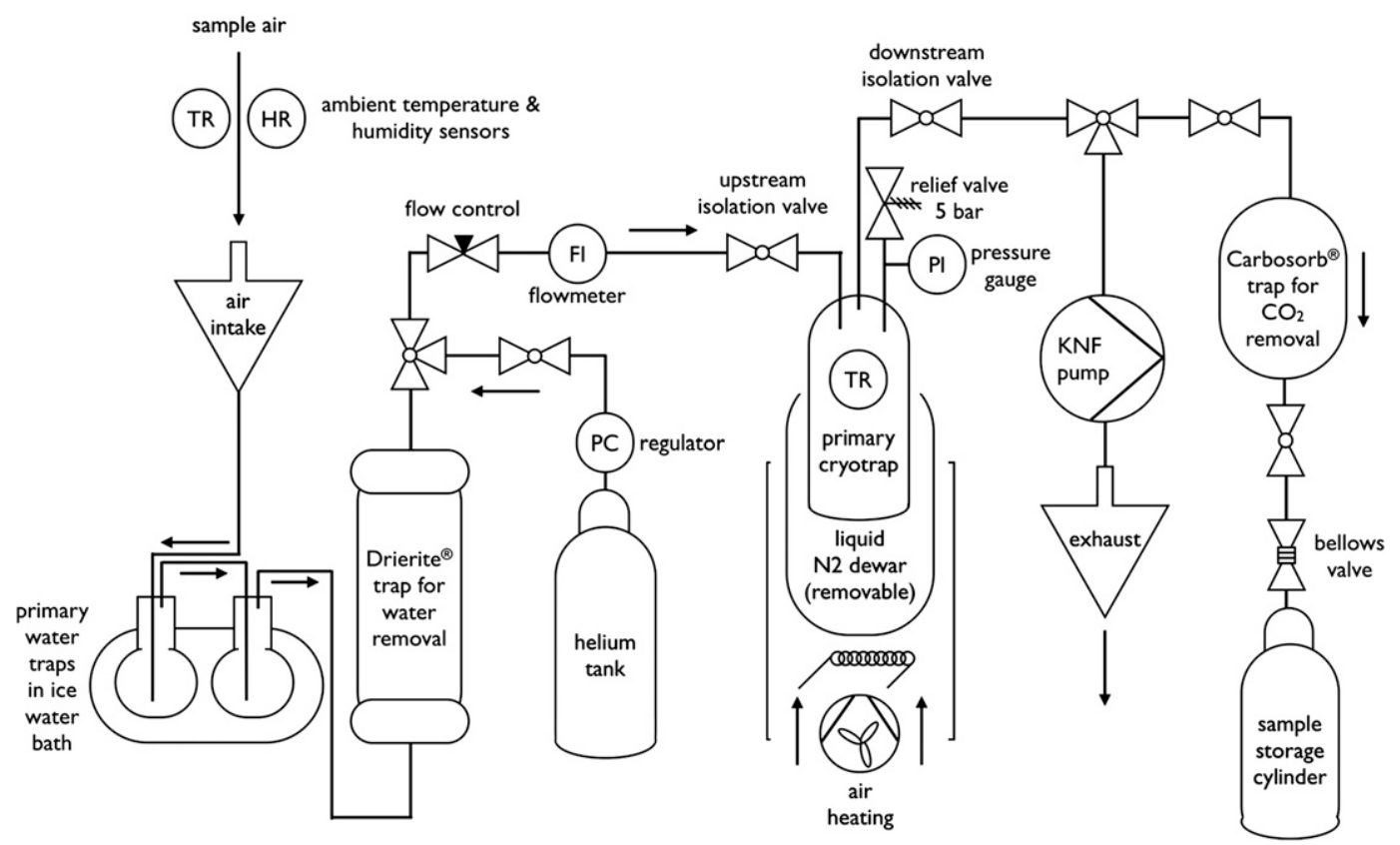

FIG. 1. Cryosampling system overview. The system is described in detail in section 2a of the text. Details of the primary cryotrap are shown in Fig. S1 of the supplemental material. The sample storage cylinder is used for transfer to the cleanup system that is shown in Fig. 2, below.

encounters the secondary drying unit. This is a "Laboratory Gas Drying Unit" containing $1.25 \mathrm{lb}(550 \mathrm{~g})$ of 8-mesh Drierite (anhydrous calcium sulfate; W.A. Hammond Drierite Co., Xenia, Ohio). The system uses two types of Drierite, the pure $\mathrm{CaSO}_{4}$ type and the $\mathrm{CaSO}_{4}$ type with a $<2 \%$ admixture of $\mathrm{CoCl}_{2}$, or "indicating Drierite," which is blue and turns to a purple-magenta color when it needs to be renewed. Drierite reacts with atmospheric water vapor extremely rapidly, drying air to a dewpoint of approximately $-70^{\circ} \mathrm{C}$. Numerous previous studies sampling air have used Drierite to remove water from the sample stream, including studies that subsequently performed isotopic analysis on trapped halocarbons from air (e.g., Bill et al. 2004, 2002; Huff et al. 1997). Drierite was chosen over alternatives because of the simplicity of operation. Using the primary drying unit before the Drierite means that, in most cases, a 6-h sample can be collected without replenishing the Drierite. Sampling in high-humidity conditions naturally would require more Drierite or more frequent swaps.

After the water is removed, dry air flows through a 20-cm 1/4-in. stainless steel tube to the first Swagelok (Solon, Ohio) three-way valve (SS-42GSX4-1466) and then through the upstream isolation valve (Swagelok SS42GS4-1466) and into the inlet of the primary cryotrap. A Kytölä Instruments (Muurame, Finland) EK-5ER flowmeter is placed upstream of the cryotrap to measure the airflow through the system (approximately $5 \%$ full-scale accuracy). After the flowmeter, the air enters the cryotrap via the upstream selection valve (controls whether helium or external air is being admitted to the system) and the upstream isolation valve, used to close the cryotrap.

The cryotrap itself is a stainless steel cylinder with a nominal interior volume of $1.1 \mathrm{~L}$ (supplemental Fig. S1). It is approximately $30 \mathrm{~cm}$ tall. Approximately $150 \mathrm{~mL}$ of the interior volume is occupied by the lift tube in the center, and approximately $15 \mathrm{~mL}$ is occupied by the thermocouple probe. The accessible trap volume, except for the lift tube, is filled with borosilicate glass beads (Merck, Darmstadt, Germany) of 5-mm diameter, with a frosted surface. A side port with a $1 / 2$-in. National Pipe Thread Taper (NPT) plug is provided for loading/ replacing/cleaning the glass-bead packing material. Assuming typical sphere packing efficiency, $74 \%$ of the space is taken up by the glass beads. This means that the gas volume inside the trap is approximately $265 \mathrm{~cm}^{3}$. The pressure inside the primary cryotrap is monitored with a Swagelok PGI-100B-BC3 pressure gauge with a 0-5 atm $(1 \mathrm{~atm}=1013.25 \mathrm{hPa})$ range.

Air enters the primary cryotrap on the outer, coldest portion of the cylinder, from the top. Air then flows down through the glass beads, where it is cooled, and volatiles are trapped on the surface of the glass beads. At the bottom of the primary cryotrap, air is pulled into the center of the cryotrap and the lift tube. Air rises up 
TABLE 2. Cryosampler construction and operating parameters.

\begin{tabular}{|c|c|}
\hline Primary cryotrap construction & Welded 3-mm stainless steel \\
\hline Connecting tubes & 1/4-in. stainless steel $(0.635 \mathrm{~cm})$ \\
\hline Coolant & Liquid nitrogen ( $20 \mathrm{~L}$ for 4 -h sample) \\
\hline Primary cryotrap packing material & $\begin{array}{l}\text { 5-6-mm frosted glass beads (Merck); 690-mL } \\
\text { total bead volume }\end{array}$ \\
\hline Sample storage & $\begin{array}{l}\text { 2580-mL passivated stainless steel cylinders } \\
\text { with Swagelok bellows valves }\end{array}$ \\
\hline Sample airflow rate & $15 \mathrm{Lmin}^{-1}$ \\
\hline Precooling cryotrap air flush time & $15 \mathrm{~min}$ \\
\hline Cryotrap cooldown time (from $\sim 20^{\circ}$ to $-180^{\circ} \mathrm{C}$ ) & $60 \mathrm{~min}$ \\
\hline Precooling duration & $30-45 \mathrm{~min}$ \\
\hline Nominal sample collection cycle time & $4 \mathrm{~h}$ \\
\hline Internal trap temperature at collection start & $-180^{\circ} \mathrm{C}$ \\
\hline Trap internal volume (total; available) & $1.1 \mathrm{~L} ; 265 \mathrm{~mL}$ \\
\hline $\begin{array}{l}\text { Internal temperature maintenance at } 15 \mathrm{~L} \mathrm{~min}^{-1} \text { flow, } 5^{\circ} \mathrm{C} \text { sample air temperature, } \\
\text { and } 20^{\circ} \mathrm{C} \text { ambient temperature (i.e., time before refilling of liquid nitrogen } \\
\text { around primary cryotrap) }\end{array}$ & $\sim 4 \mathrm{~h}$ \\
\hline Drierite trap endurance at $5^{\circ} \mathrm{C}$ and $30 \%$ relative humidity with 550 -g adsorbent load & $\sim 6 \mathrm{~h}$ \\
\hline $\begin{array}{l}\text { Time for primary cryotrap to warm to approximately }-100^{\circ} \mathrm{C} \text { after removal from } \\
\text { liquid nitrogen }\end{array}$ & $\sim 1 \mathrm{~h}$ \\
\hline $\begin{array}{l}\text { Primary cryotrap pump-down duration (temperature }<-150^{\circ} \mathrm{C} \text { ), escaping any } \\
\text { trapped } \mathrm{O}_{2}, \mathrm{~N}_{2} \text {, other cotrapped gases }\end{array}$ & $\sim 10-15 \mathrm{~min}$ \\
\hline $\begin{array}{l}\text { Time to raise primary cryotrap temperature with } 2000-\mathrm{W} \text { air heating from }-100^{\circ} \\
\text { to } 50^{\circ} \mathrm{C}\end{array}$ & $1 \mathrm{~h}$ \\
\hline
\end{tabular}

through the lift tube and is pulled out of the primary cryotrap. There are two additional connections into the primary cryotrap: a $28-\mathrm{cm}$ thermocouple probe tube, for monitoring the interior cryotrap temperature, and an additional port connected to a Swagelok SS-RL3S4-MO relief valve, which is set to automatically open if the pressure exceeds $\sim 5$ bar $(5000 \mathrm{hPa})$ and can be manually opened to rapidly depressurize the system if necessary. An additional surface thermocouple is attached to the exterior near the inlet of the cryotrap, above the level of liquid nitrogen, to monitor the "warmest" spot on the cryotrap.

Air exiting the primary cryotrap passes the downstream cryotrap isolation valve and the downstream three-way selection valve (selects flow to the KNF pump or to the carbon dioxide removal unit). After air exits the primary cryotrap, it passes through a downstream isolation valve (Swagelok SS-42GS4-1466), used for isolating the cryotrap and then to the KNF pump, where it is exhausted. During sampling, air exiting the cryotrap is exhausted by the pump. During sample transfer to storage cylinders, the downstream three-way valve is turned to direct the flow away from the KNF pump and to a Carbosorb (Sigma-Aldrich, Stockholm, Sweden) trap. The Carbosorb trap is a 75-mL double-ended Swagelok stainless steel cylinder filled with Carbosorb, a carbon dioxide chemical adsorbant consisting of $\mathrm{NaOH}$ on silica, with additional Swagelok ball valves on either side of the Carbosorb trap (to facilitate swapping the Carbosorb trap without depressurizing the system).
The cryotrap itself sits in a liquid nitrogen bath in a 10-L glass vacuum Dewar flask during sampling. After the liquid nitrogen Dewar flask is removed, $2000 \mathrm{~W}$ of forced-air heat is available for rapidly warming the cryotrap for desorbing the trapped gases.

The final element of the system is the helium tank and storage cylinder. The helium tank is used to flush the collected and desorbed sample from the cryotrap and into the storage cylinder. Storage cylinders are evacuated 2580-mL well-conditioned (passivated) stainless steel cylinders (Opsis AB, Furulund, Sweden). The storage cylinders are connected via Swagelok tubing connectors and are closed using Swagelok bellows valves (SS-4H2).

The temperatures measured by the thermocouple probe inside the primary cryotrap during a complete sampling cycle are shown schematically in Fig. S2 of the supplemental material, with both target ideal temperatures and measured actual temperatures. In operation, ambient relative humidity and temperature and cryotrap exterior temperature are also monitored.

\section{b. HAVOC cryotrap cooling and sampling phase}

To obtain quantities of $\mathrm{CH}_{3} \mathrm{Br}$ sufficient to analyze each sample for bromine two or three times (given the LOQ), the cryotrap system is operated at a $15 \mathrm{Lmin}^{-1}$ pumping rate for $4 \mathrm{~h}$. In this time the HAVOC system traps over $100 \mathrm{ng}$ of $\mathrm{Br}$ as $\mathrm{CH}_{3} \mathrm{Br}$ and over $4000 \mathrm{ng}$ of $\mathrm{Cl}$ as $\mathrm{CH}_{3} \mathrm{Cl}$ from typical atmospheric air (Table 1). A sampling cycle begins with a 15-min (or longer) purge of the system, pumping sample air at the maximum flow rate of 
about $25 \mathrm{~L} \mathrm{~min}^{-1}$ through the cryotrap at ambient temperatures. Airflow is then directed through the condensation trap, followed by the Drierite trap, the cryotrap, and finally through the diaphragm pump (Fig. 1).

The initial cooldown of the cryotrap prior to sampling is performed with an internal helium load to increase the cooling rate. At the end of the purge stage, the upstream isolation valve is closed. After the pump decreases the interior pressure to $100 \mathrm{hPa}$, the downstream isolation valve is closed as well. Now the upstream valve is reopened to fill the trap with helium to atmospheric pressure. The upstream valve is closed. The cryotrap is cooled by placing it in a liquid nitrogen bath in a 10-L Dewar flask. The complete initial cooldown to an internal cryotrap temperature of $-180^{\circ} \mathrm{C}$ takes about $1 \mathrm{~h}$.

The sampling phase begins by setting the three-way valves for sampling, starting the pump, and opening the downstream isolation valve, followed by the upstream isolation valve. Airflow is adjusted to $15 \mathrm{~L} \mathrm{~min}^{-1}$ using the needle valve. In normal trapping operation, the flow control valve and isolation valves are adjusted to maintain a pressure of $500 \mathrm{hPa}$ in the trap (running at slight underpressure avoids some cotrapping of nontarget compounds).

Liquid nitrogen is replenished approximately every 2-3 h for sampling flow rates of $15 \mathrm{~L} \mathrm{~min}^{-1}$. Because of the high thermal conductivity of the stainless steel cryotrap, the internal temperature is maintained even as the level of liquid nitrogen drops to as low as one-half of the height of the primary cryotrap. The internal thermocouple measures temperatures deep within the primary cryotrap, and an external thermocouple measures the temperature near the top-the warmest part, which allows us to ensure that stable low temperatures are maintained. A 6-h sampling cycle consumes approximately $30 \mathrm{~L}$ of liquid nitrogen in total; this is including liquid nitrogen used for initial cooling of the primary cryotrap (samples taken in series consume approximately $20 \mathrm{~L}$ per sample).

In normal operation, we swapped out primary cryotraps approximately every 20 samples. The traps were cleaned with deionized water. The glass beads were cleaned in an ultrasonic bath and dried in a kiln before reassembling the traps. We observed no changes in the recovered amounts of methyl halides in our synthetic mixtures after these cleanings. Additionally, we never saw sequentially increasing recoveries of methyl halides during the 20-sample sequence between cleanings.

\section{c. Desorption of $\mathrm{CH}_{3} \mathrm{Br}$ from $\mathrm{HAVOC}$ and storage phase}

After the sampler has been operated for the desired duration, the upstream isolation valve to the primary cryotrap is closed. The pump continues to run for $10 \mathrm{~min}$ to reduce the pressure in the primary cryotrap. The cryotrap is removed from the liquid nitrogen bath. The pump continues to run while the trap is below $-150^{\circ} \mathrm{C}$; this step removes some of the more volatile trapped components, including any oxygen and nitrogen. The downstream isolation valve is closed, and the diaphragm pump is stopped.

As the cryotrap is removed from liquid nitrogen, the system is further warmed and is now in the desorption/ storage phase. The exterior of the primary cryotrap is heated until its interior temperature reaches $50^{\circ} \mathrm{C}$; this heating takes approximately $45 \mathrm{~min}-1 \mathrm{~h}$ using $2000 \mathrm{~W}$ of external air heating. The pressure in the cryotrap during this warming typically rises from about 100 to around $1250 \mathrm{hPa}$.

\section{d. Helium-assisted fast transfer from cryotrap to storage cylinders}

The helium-flushed transfer of the samples out of the heated cryotrap is accomplished while maintaining the cryotrap at $50^{\circ} \mathrm{C}$. The storage cylinder and the line between the cylinder and the cryotrap are evacuated, and then the bellows valve on the cylinder is opened, followed by opening the downstream isolation valve and moving the downstream three-way valve to the "storage/purge" position (see Fig. 1). Because of the low pressure in the storage cylinder and the higher volume (approximately 10 times the available volume in the cryotrap), most of the sample is transferred in this first push-within about 1 min-to allow for contact time with the $\mathrm{CO}_{2}$-trap packing material (Carbosorb). The sample flows through the Carbosorb trap on its way to the storage cylinder. The downstream isolation valve is closed, and then the helium is used to pressurize the cryotrap to $1 \mathrm{~atm}$ through the upstream isolation valve. After the helium flow is stopped and the upstream isolation valve is closed, the downstream valve is opened again for a second to flush another volume of the helium-sample mixture into the storage cylinder. This process is repeated five more times, building up to an ultimate pressure in the cryotrap cylinder at the last step of about $1500 \mathrm{hPa}$ and a final pressure in the storage cylinder of $1000 \mathrm{hPa}$. In this way, at least $93.75 \%$ of the sample is physically blown out of the cryotrap, using the helium carrier gas. Last, the storage cylinder bellows valve is closed; the cylinder is removed from the system, and the cylinder valve secured with an additional gas-tight cap for transport. At this point, after the sample storage is completed, the system is purged by flowing air through the system at maximum flow rate for $1 \mathrm{~h}$ while the cryotrap is still hot. This removes most volatile residual contaminants and prepares the system for the next collection cycle. 


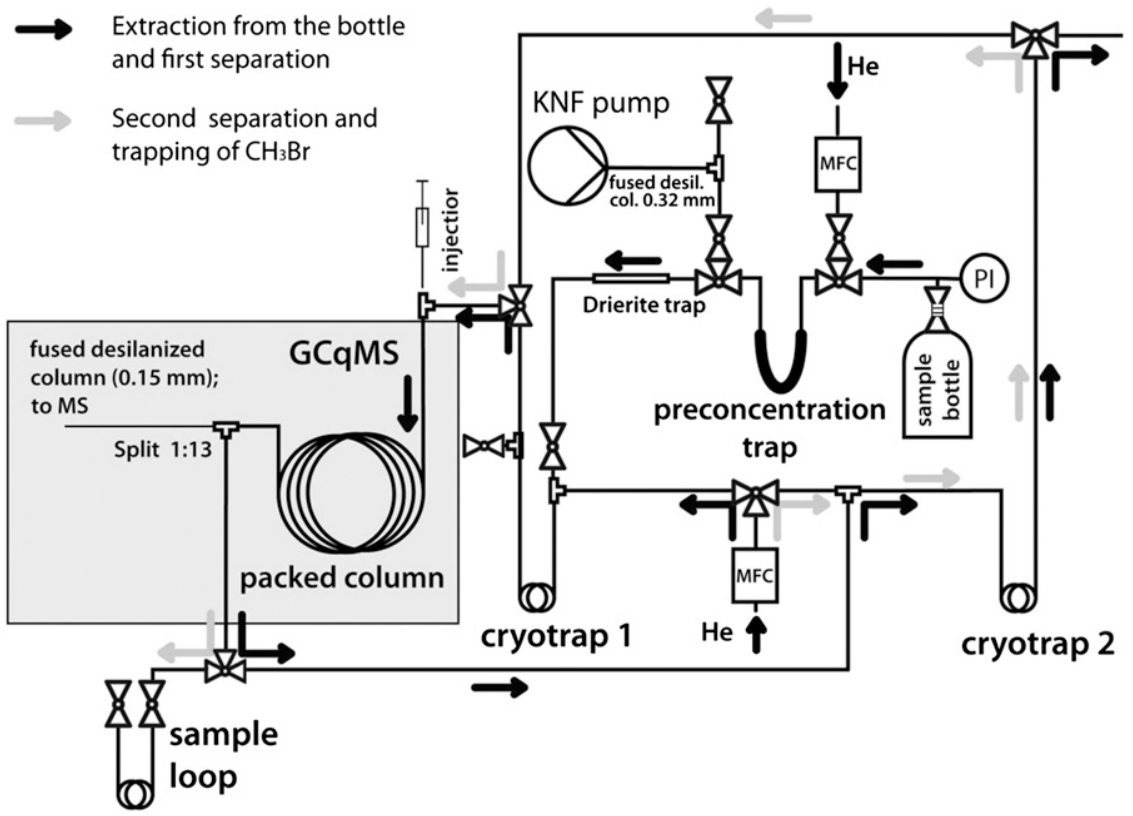

FIG. 2. Sample cleanup system overview. A sample from the cryosampling system in Fig. 1 is delivered in the sample bottle shown above. The sample bottle is flushed into the preconcentration trap using helium, then is dried, and is routed through cryotrap 1. A packed column in a GCqMS (see text for details) is used to isolate the $\mathrm{CH}_{3} \mathrm{Br}$ peak. This isolated peak is then routed back through the cryotraps for more purification or is routed to the sample loop. The sample loop is used to transport the cleaned sample to the GC-ICP-mcMS system for bromine isotope analysis.

\section{e. Sample separation and purification}

Before a sample can be injected into the GCqMS system or the GC-ICP-mcMS system, remaining interfering components of the large atmospheric matrix should be removed. Although the cryosampler removes $\mathrm{O}_{2}, \mathrm{~N}_{2}$, $\mathrm{Ar}$, and the majority of $\mathrm{CO}_{2}$ and water vapor, other atmospheric species are still present, including a large amount of $\mathrm{N}_{2} \mathrm{O}$. Further purification of the collected samples is performed using preparative chromatography on a packed column [60/80 Carbopack B/1\% SP-1000 (polyethylene glycol); 96 in. $\times 1 / 8$ in. steel column $(243.8 \mathrm{~cm} \times 0.32 \mathrm{~cm})]$ and with sequential liquid nitrogen-cooled cryotraps; both are housed in a retrofitted GCqMS instrument [gas chromatograph (GC): Agilent (Santa Clara, California) G1530A; mass spectrometer (MS): Agilent HP5972A]. The entire sample cleanup procedure is shown schematically in Fig. 2 and is described in more detail in the supplemental material (supplemental sections 2 and 3, Tables S1 and S2, and Fig. S3). In brief, a microdiaphragm pump (KNF Neuberger model NMP 830 KNDC) is used to transfer the sample gas from the canister to the liquid nitrogen-cooled preconcentration trap. The canister is pumped down to a pressure of $500 \mathrm{hPa}$ and refilled with helium again. This procedure is repeated five times, which transfers more than $93.75 \%$ of the sample. To obtain better compound separation, the sample is transferred to the smaller cryotrap 1 and from there, by heating, is released onto the column. The GC is operated at constant temperature $\left(30^{\circ} \mathrm{C}\right)$ and pressure $(1800 \mathrm{hPa})$. After separation, $8 \%$ of the sample is transferred via a custom-made split to the MS for quantification. The MS is operated in ion selective mode for molecular mass to number of elementary charges ratio $\mathrm{m} / \mathrm{z}$ of 50 for $\mathrm{CH}_{3} \mathrm{Cl}$ (retention time is $210 \mathrm{~s}$ ), and $\mathrm{m} / \mathrm{z}$ of 94 for $\mathrm{CH}_{3} \mathrm{Br}$ (retention time is $420 \mathrm{~s}$ ). The limit of detection of this GCqMS system is $0.06 \mathrm{ng} \mathrm{CH}_{3} \mathrm{Cl}$ and $0.35 \mathrm{ng} \mathrm{CH}_{3} \mathrm{Br}$, although more is required for isotope analysis. Nitrous oxide and $\mathrm{CO}_{2}$ (both of mass 44 ), as well as oxygen (mass 32), nitrogen, and water (mass 18), were identified as the main interfering compounds and are also monitored. After the first separation step, the target compounds are cut out by switching valves and are collected in cryotrap 2. The system allows for recirculation of the compounds into the packed column again and for separate trapping of $\mathrm{CH}_{3} \mathrm{Br}$ and $\mathrm{CH}_{3} \mathrm{Cl}$. Two cleanup cycles are sufficient to remove most of the interfering substances. The cleaned samples, ready for isotope analysis, are stored in passivated 50-cm-long $1 / 8$-in. $(3.2 \mathrm{~mm})$ stainless steel loops sealed with Swagelok plugs. 


\section{f. Isotope analysis system}

Isotopic composition and fractionation are by convention reported in per mill using the $\delta$ notation, which refers to the deviation of the isotope ratio (e.g., $R=$ ${ }^{37} \mathrm{Cl} /{ }^{35} \mathrm{Cl}$ ) between the sample and a reference material for the given isotope system (generally seawater, e.g., "standard mean ocean chloride"). The result of Eq. (1) is in per mill $(\%)$ notation. If one sets $R={ }^{81} \mathrm{Br} /{ }^{79} \mathrm{Br}$, then one obtains the similar equation for bromine [Eq. (2)]. Bromine isotope fractionations may be similarly referenced to standard mean ocean bromide (SMOB; Eggenkamp and Coleman 2000):

$$
\begin{aligned}
\delta^{37} \mathrm{Cl} & =\left(R_{\text {sample }} / R_{\text {reference }}-1\right) \times 1000 \text { and } \\
\delta^{81} \mathrm{Br} & =\left(R_{\text {sample }} / R_{\text {reference }}-1\right) \times 1000 .
\end{aligned}
$$

In this text, we also use the $\Delta^{81} \mathrm{Br}$ notation when we are referring to the deviation of the bromine isotope ratio between a standard before and after processing through our collection and purification systems (the difference between two bromine isotope ratios, not linked to an external reference material; Coplen 2011).

The $\mathrm{Br}$ isotope analysis method employed here has been described in detail previously (Horst et al. 2011) and is only briefly summarized below. First, the purified sample stored in the $1 / 8$-in. steel sample loop is flushed out with a small helium flow, transferring it into the GC-ICP-mcMS system. The sample is first cryofocused (Smart Cryo, Weatherford Laboratories, Humble, Texas) (cooling mode) at $-180^{\circ} \mathrm{C}$ and released (heating mode) at $150^{\circ} \mathrm{C}$, before entering the GC. The GC positioned as a front end to the inductively coupled plasma (ICP) system is a Hewlett-Packard 5890 Series II (Agilent). The GC column utilized is a "megabore" capillary column $30 \mathrm{~m}$ in length, $0.53 \mathrm{~mm}$ in inner diameter, and $0.5 \mu \mathrm{m}$ in film thickness, with cross-linked $5 \%$ phenylmethylpolysiloxane (Factor Four, Varian, Walnut Creek, California). The column temperature is held at $70^{\circ} \mathrm{C}$. On exiting the GC, the sample travels through a heated $\left(105^{\circ} \mathrm{C}\right)$ transfer line to a nebulizer before the ICP torch. After ionization and separation, two mass traces (79 and 81) were recorded simultaneously. Integration and isotope ratio calculation were performed by a script written with MATLAB proprietary software.

\section{Performance testing of the HAVOC cryosampler and the purification system}

Both the cryogenic sampling system and the sample purification system were evaluated with respect to both mass yield and any method-induced isotope fractionation.

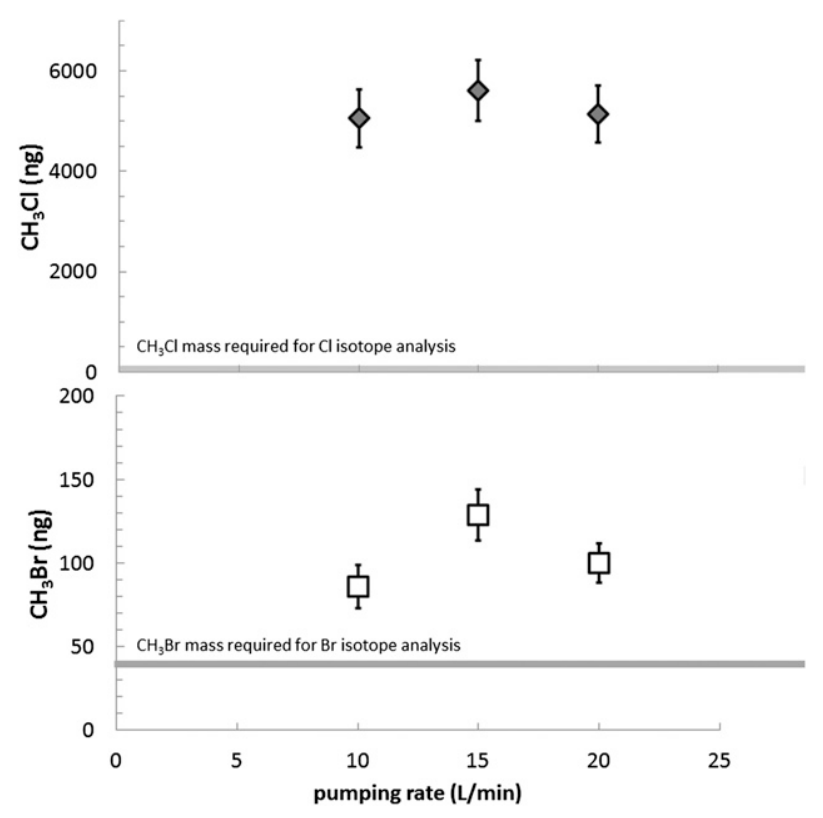

FIG. 3. Recovery of (top) $\mathrm{CH}_{3} \mathrm{Cl}$ and (bottom) $\mathrm{CH}_{3} \mathrm{Br}$ from atmospheric samples collected in July, September, and October 2011 in Stockholm, Sweden. Samples were of equal total sample volume $(4800 \mathrm{~L})$ but varying sampling time because of different sampling rates. Samples were quantified using the GCqMS system described in the text and were compared with standard mixtures of known concentration. Markers indicate the mass of $\mathrm{CH}_{3} \mathrm{X}$ recovered at various pumping rates. Variability in recovered quantities may be due to atmospheric or sampling system variability and is addressed in other tests described in the text. The thick gray lines represent the amount of $\mathrm{CH}_{3} \mathrm{X}$ required for isotopic analysis via GCqMS ( $\mathrm{Cl}$ isotopes) or GC-ICP-mcMS ( $\mathrm{Br}$ isotopes). Error bars indicate a 1- $\sigma$ propagated uncertainty range for our results. The 10 , 15 , and $20 \mathrm{~L} \mathrm{~min}^{-1}$ data points are based on 4,3 , and 2 independent samples, respectively.

Results from previous studies suggest the absence of any significant isotope fractionation for similar target molecules with this type of cryogenic system (Bahlmann et al. 2011). Nevertheless, substantial efforts were invested to validate this crucial aspect specifically for the herein-developed system and target analytes.

The system performance was verified in four ways: first, the suitability of the cryotrap was evaluated by sampling ambient atmospheric air and analysis of the amounts of $\mathrm{CH}_{3} \mathrm{Cl}$ and $\mathrm{CH}_{3} \mathrm{Br}$ collected (Fig. 3); second, the purification system was evaluated for efficiency and lack of isotope fractionation by analysis of concentrations and isotope composition of $\mathrm{CH}_{3} \mathrm{Br}$; and third, the complete system (cryotrap and purification system) was evaluated by processing synthetic air standards with known concentrations and isotope composition of a $\mathrm{CH}_{3} \mathrm{Br}$ standard. In this third test, single synthetic samples were processed through the cryotrap and purification system, with the initial and final $\delta^{81} \mathrm{Br}_{-} \mathrm{CH}_{3} \mathrm{Br}$ 
compared. Fourth, the application of the full system for $\delta^{81} \mathrm{Br}-\mathrm{CH}_{3} \mathrm{Br}$ was demonstrated by application to ambient atmospheric samples from the suburban atmosphere at Stockholm University.

\section{a. Ability and efficiency of HAVOC collecting $\mathrm{CH}_{3} \mathrm{Br}$ and $\mathrm{CH}_{3} \mathrm{Cl}$ from ambient atmospheric air}

Testing of the sampling-time and pumping-rate operating parameters of the HAVOC cryosampler was first explored by comparing the actual amount (mass) of trapped methyl halides with the approximate amount expected from ambient air. The aim of this test was to prove the ability of the cryosampler to collect sufficient amounts of $\mathrm{CH}_{3} \mathrm{Br}$ for subsequent $\delta^{81} \mathrm{Br}_{-} \mathrm{CH}_{3} \mathrm{Br}$ analysis. Samples were collected using the cryosampling system in July, September, and October 2011 in Stockholm, Sweden (Stockholm University campus); the samples were not collected sequentially. The pumping rate had an upper limit set by the pump and the airflow resistance of the sampler-approximately $25 \mathrm{~L} \mathrm{~min}^{-1}$. The lower limit is set to avoid inconveniently long sampling times. Hence, in obtaining $\mathrm{CH}_{3} \mathrm{Br}$ samples for isotope analysis, the sampler was tested at 10 (four samples), 15 (three samples), and 20 (two samples) $\mathrm{L} \mathrm{min}^{-1}$ pumping rates, each processing the same total amount of air $(4800 \mathrm{~L})$ but with different pumping durations. The results of these pumping tests are shown in Fig. 3. The samples were collected as described in section 2 above, transferred into the 2.58-L stainless steel storage cylinders, and analyzed within 1 week.

However, it is known that the ambient concentrations of methyl halides may vary by a factor of 2 or more on a short time scale because of transient pollution or local source events and on a longer time scale because of seasonal variability (Yvon-Lewis et al. 2009). Thus, there may have been considerable variability during our multihour sampling periods. However, this test still validated the sampler's ability to capture large amounts of methyl halides from the atmosphere. In this test, there was no apparent trend over the tested flow rates (sampling durations), and it was decided that $15 \mathrm{~L} \mathrm{~min}^{-1}$ would be used as the standard pumping rate to minimize sampling duration. To truly know the sampler's efficiency, testing with synthetic air is required, and we describe that test in section $3 \mathrm{c}$ below.

\section{b. Tests for recovery and isotope fractionation in the separation and purification system}

To check the collection efficiency and lack of induced isotope fractionation of the separation and purification procedure, synthetic mixtures of the target compounds $\mathrm{CH}_{3} \mathrm{Cl}$ and $\mathrm{CH}_{3} \mathrm{Br}$ with the nontarget but often cotrapped compounds $\mathrm{CO}_{2}$ and $\mathrm{N}_{2} \mathrm{O}$ were prepared and injected into the separation system. These mixtures were designed to be comparable in mixing ratios to actual atmospheric samples produced from the HAVOC cryosampler system but with absolutely known concentrations. (Because the concentration of the target compounds increases during the separation and purification process, the mixtures have different concentrations depending on which step of the separation and purification process we were testing, as described below.) These set of tests were performed to address four possible concerns. The system was flushed thrice with helium between each sample tested.

The first concern is the efficiency of cryotraps 1 and 2 as well as the preconcentration trap. These traps were tested separately by injecting standard mixtures of 20 ppmv $\mathrm{CH}_{3} \mathrm{Cl}$ and 2 ppmv $\mathrm{CH}_{3} \mathrm{Br}$ in helium into the purification system (Fig. 2) and testing the effect of varying flow rates through the traps in the range 10 $500 \mathrm{~mL} \mathrm{~min}^{-1}$ (Table 3 ). Recoveries were determined by desorbing the mixtures from the cryotraps into the GCqMS system. Recoveries statistically indistinguishable from $100 \%$ were consistently obtained for flow rates of 10-50 $\mathrm{mL} \mathrm{min}^{-1}$ for all components (cryotrap 1, cryotrap 2 , and preconcentration trap) as well as after four full purification cycles (Table 3). Lower recoveries were increasingly seen for flow rates of $100 \mathrm{~mL} \mathrm{~min}^{-1}$ and above. It was concluded that high efficiency for $\mathrm{CH}_{3} \mathrm{Br}$ and $\mathrm{CH}_{3} \mathrm{Cl}$ was obtainable with this purification system for sample flow rates of $10 \mathrm{~mL} \mathrm{~min}^{-1}$.

The second concern is the capacity of the GC packed column used in the separation step. It is conceivable that for large amounts of methyl halides and cotrapped compounds the efficiency might decrease because of the column capacity being exceeded, which in turn could alter elution times and peak shapes and could possibly affect recoveries and cause isotope fractionation. For testing, we used a synthetic standard mixture representing typical recovery from the cryosampler and containing $50 \% \mathrm{~N}_{2} \mathrm{O}, 20 \% \mathrm{CO}_{2}, 1500$ ppmv $\mathrm{CH}_{3} \mathrm{Cl}$, and $20 \mathrm{ppmv}$ $\mathrm{CH}_{3} \mathrm{Br}$, with the balance being helium. A 2-mL volume of such a standard mixture contains approximately the expected amount of $\mathrm{CH}_{3} \mathrm{Br}$ and $\mathrm{CH}_{3} \mathrm{Cl}$ in $4 \mathrm{~m}^{3}$ of airabout the sample size obtained in $4 \mathrm{~h}$ of atmospheric sampling. Two-milliliter aliquots were injected into the sample separation system and eluted through the packed column. Recoveries were measured using the attached GCqMS. The recovery efficiency from the packed column was $102 \% \pm 2.3 \%(1 \sigma ; n=4)$ for $\mathrm{CH}_{3} \mathrm{Cl}$ and $107.1 \% \pm 2.3 \%(1 \sigma ; n=4)$ for $\mathrm{CH}_{3} \mathrm{Br}$. Similar testing was conducted with mixtures containing only $\mathrm{CH}_{3} \mathrm{Cl}$ and $\mathrm{CH}_{3} \mathrm{Br}$, with the balance being $\mathrm{He}$. With these mixtures, high recoveries statistically indistinguishable from $100 \%$ were also maintained for wide ranges of 20-2000 ppmv 
TABLE 3. Efficiency testing of methyl halide recoveries from key components/stages of the sample purification system using a realistic matrix with $\mathrm{CO}_{2}$ and $\mathrm{N}_{2} \mathrm{O}$ as interfering substances and varying flows.

\begin{tabular}{|c|c|c|c|c|c|}
\hline \multirow[b]{2}{*}{ Component } & \multirow[b]{2}{*}{ Flow through the trap $\left(\mathrm{mL} \min ^{-1}\right)$} & \multicolumn{2}{|c|}{$\mathrm{CH}_{3} \mathrm{Cl}$} & \multicolumn{2}{|c|}{$\mathrm{CH}_{3} \mathrm{Br}$} \\
\hline & & Efficiency (\%) & $1 \sigma(n=3 ; \%)$ & Efficiency $(\%)$ & $1 \sigma(n=3 ; \%)$ \\
\hline Cryotrap 1 & 10 & 103.0 & 2.2 & 97.8 & 1.4 \\
\hline Cryotrap 2 & 10 & 100.2 & 4.0 & 104.2 & 2.8 \\
\hline Yield after four cycles & 10 & 98.4 & 1.6 & 97.6 & 2.4 \\
\hline \multirow[t]{5}{*}{ Preconcentration trap } & 10 & 104.7 & 12.2 & 106.5 & 6.4 \\
\hline & 50 & 107.9 & 7.1 & 99.3 & 9.0 \\
\hline & 100 & 85.9 & 6.8 & 91.9 & 5.1 \\
\hline & 200 & 78.0 & 2.6 & 82.6 & 6.5 \\
\hline & 500 & 56.5 & 2.6 & 56.4 & 2.7 \\
\hline
\end{tabular}

$\mathrm{CH}_{3} \mathrm{Cl}$ and 20-200 ppmv $\mathrm{CH}_{3} \mathrm{Br}$ (see Table S1 and Fig. S3 in the supplemental material). Our actual atmospheric samples are predominantly helium in the transfer cylinders. It was therefore concluded that quantitative recoveries of $\mathrm{CH}_{3} \mathrm{Cl}$ and $\mathrm{CH}_{3} \mathrm{Br}$ were demonstrated over a wide range of relevant sample sizes.

A third concern is the efficiency of the transfer of the HAVOC cryotrapped samples from the 2.58-L transfer cylinders to the preconcentration trap using the KNF microdiaphragm pump. A synthetic standard sample $\left(2 \mathrm{~mL} ; 50 \% \mathrm{~N}_{2} \mathrm{O}, 20 \% \mathrm{CO}_{2}, 1500\right.$ ppmv $\mathrm{CH}_{3} \mathrm{Cl}$, and 20 ppmv $\mathrm{CH}_{3} \mathrm{Br}$ in helium) was injected into a $2.58-\mathrm{L}$ canister and transferred to the preconcentration trap by pumping it five times down to $500 \mathrm{hPa}$, filling with helium between each pumping cycle (see section 2 of the supplemental material). The efficiency of removing samples from the transfer cylinders with this procedure is $83 \% \pm 2.7 \%(1 \sigma ; n=3)$ for $\mathrm{CH}_{3} \mathrm{Cl}$ and $90 \% \pm 2.8 \%$ $(1 \sigma ; n=3)$ for $\mathrm{CH}_{3} \mathrm{Br}$, when compared with the same synthetic sample directly injected onto the packed column GCqMS. Given analytical uncertainties, these yields are reasonable. For our purposes $500 \mathrm{hPa}$ is the compromise between fast sample treatment and sufficient yield.

Fourth, while mass recovery is important, it is crucial to ascertain that there are no large isotope effects induced by the separation and purification system. To directly test for any $\mathrm{Br}$ isotope effects during sample purification, we measured the $\Delta^{81} \mathrm{Br}-\mathrm{CH}_{3} \mathrm{Br}$ of standard samples both before and after the preconcentration trap and first cryotrap. To this end, we compared the $\Delta^{81} \mathrm{Br}-\mathrm{CH}_{3} \mathrm{Br}$ obtained with the low $10 \mathrm{~mL} \mathrm{~min}^{-1}$ flow (Table 3) with the isotope signal obtained at higher flow rates with lower mass recoveries. For initial transfer flows of 100,500 , and $1500 \mathrm{~mL} \mathrm{~min}^{-1}$, the $\Delta^{81} \mathrm{Br}-\mathrm{CH}_{3} \mathrm{Br}$ signal was not observed to significantly change relative to sample transfer at $10 \mathrm{~mL} \mathrm{~min}^{-1}$ (Table 4), despite increasing sample losses at higher flow rates (over $40 \%$ at the highest flows). We thus conclude that the separation and purification system is free from any appreciable method-induced
Br isotope effects. Taken all together, the separation and purification system appears to produce high yields with high integrity in isotopic signals for methyl bromide.

\section{c. Verification of lack of isotope fractionation in the entire cryotrapping-purification system}

The entire chain of procedures from cryogenic sampling, all transfer steps through purification and onward to isotope analysis, was evaluated for conservation of the bromine isotope ratio. To this end, three synthetic $\mathrm{CH}_{3} \mathrm{Br}$ gas samples $\left(20\right.$ ppmv $\mathrm{CH}_{3} \mathrm{Br} / 1500$ ppmv $\left.\mathrm{CH}_{3} \mathrm{Cl}\right)$ with $\Delta^{81} \mathrm{Br}$ set to be zero were introduced to the HAVOC sampler from a 0.5-L Tedlar bag while slowly mixing/diluting with a pure $\mathrm{N}_{2}$ background gas $(2 \mathrm{~h}$ at $15 \mathrm{~L} \mathrm{~min}^{-1}$ total flow). The actual $\delta^{81} \mathrm{Br}$ relative to SMOB for our standard is close to zero; however, for this test, we are interested in the change in ratio only.

These three samples, after undergoing the cryotrapping and purification steps described above, were taken to the GC-ICP-mcMS system for $\Delta^{81} \mathrm{Br}$ analysis by following the procedure in Horst et al. (2011). The result of processing a standard mixture was an average $\Delta^{81} \mathrm{Br}$ of $0.03 \%$ o (relative to the original standard gas having $\left.\Delta^{81} \mathrm{Br}=0\right)$, with an average standard deviation $(1 \sigma)$ with error propagation of $0.10 \%$, for six injections of the three independent samples (Table 5). This absence of $\mathrm{Br}$ isotope fractionation combined with the high level of precision of the GC-ICPmcMS system to suggest that this cryotrapping-purification system is suitable for

TABLE 4. Evaluation of methyl halide recoveries and bromine isotope shift $\left(\Delta^{81} \mathrm{Br}\right)$ induced by increasing flow rates through the sample purification system for synthetic $\mathrm{CH}_{3} \mathrm{Br}$ samples $\left(\Delta^{81} \mathrm{Br}\right.$ is set to 0 for synthetic samples).

\begin{tabular}{cccc}
\hline $\begin{array}{c}\text { Flow rate } \\
\left(\mathrm{mL} \mathrm{min}^{-1}\right)\end{array}$ & $\begin{array}{c}\text { Recovery } \\
\text { efficiency }(\%)\end{array}$ & $\begin{array}{c}\Delta{ }^{81} \mathrm{Br} \text { vs sample } \\
\text { injected at } 10 \mathrm{~mL} \mathrm{~min}^{-1}\end{array}$ & $\begin{array}{c}1 \sigma \\
(n=3)\end{array}$ \\
\hline 100 & 94.9 & 0.17 & 0.20 \\
500 & 63.5 & -0.22 & 0.25 \\
1500 & 58.5 & -0.14 & 0.14 \\
\hline
\end{tabular}


TABLE 5. Evaluation of $\Delta^{81} \mathrm{Br}-\mathrm{CH}_{3} \mathrm{Br}$ of synthetic air samples processed through HAVOC cryosampler and sample purification system vs unprocessed synthetic air samples with standard $\mathrm{CH}_{3} \mathrm{Br}$ ( $\Delta^{81} \mathrm{Br}$ is set to 0 for synthetic samples).

\begin{tabular}{cc}
\hline \hline $\begin{array}{c}\Delta^{81} \mathrm{Br} \text { vs } \\
\text { unprocessed standard }\end{array}$ & $\begin{array}{c}1 \sigma \text { (with } \\
\text { error propagation) }\end{array}$ \\
\hline-0.02 & 0.09 \\
0.03 & 0.13 \\
0.10 & 0.08 \\
Avg (three samples; two injections per sample) \\
0.03 & 0.10 \\
\hline
\end{tabular}

analysis of $\delta^{81} \mathrm{Br}-\mathrm{CH}_{3} \mathrm{Br}$ in atmospheric samples (see also Fig. 4).

\section{d. Application to ambient atmospheric sampling}

To demonstrate the ability of the full system to obtain $\delta^{81} \mathrm{Br}-\mathrm{CH}_{3} \mathrm{Br}$ data from ambient air, atmospheric samples were collected at Stockholm University's Geosciences building from a balcony $10 \mathrm{~m}$ above ground level $\left(59.366^{\circ} \mathrm{N}, 18.058^{\circ} \mathrm{E}\right)$ in September and October 2011. The parameters for the 4-h sampling periods were as described above. These initial first results of ambient $\delta^{81} \mathrm{Br}-\mathrm{CH}_{3} \mathrm{Br}$ suggest values of about $\% \%-2 \%$ (relative to SMOB), between the two samples collected a week apart (Table 6). A deeper interpretation of these first results, used here only to demonstrate the applicability of the sampler and purification system, needs to await a forthcoming larger number of analyses to obtain statistical significance. The uncertainty in $\delta^{81} \mathrm{Br}$ caused by cryogenic collection of synthetic samples (gray band in Fig. 4) is small in comparison with the range covered by two ambient atmosphere samples. This difference suggests the applicability of the sampling system for $\delta^{81} \mathrm{Br}$ $\mathrm{CH}_{3} \mathrm{Br}$ from the atmosphere.

It is important to note that the cryogenic system described here has several additional applications. For instance, in addition to application toward also $\delta^{37} \mathrm{Cl}-$ $\mathrm{CH}_{3} \mathrm{Cl}$, and similarly condensable gases, it can also be used to extract methyl halides from large whole air samples rapidly collected by compression (e.g., $10^{5} \mathrm{hPa}$, 20-L cylinders; and 30 min per sample) when it is impractical to use the relatively slow cryosampler. Such large whole air samples can then be brought back from field sites and slowly flowed through the cryosampler to extract methyl halides from the whole air samples, which in some situations may be impractical in field sampling.

\section{Summary}

A robust cryogenic sampler designed to trap volatile gases from the air under demanding field conditions has been developed. The cryosampler is immersed in liquid

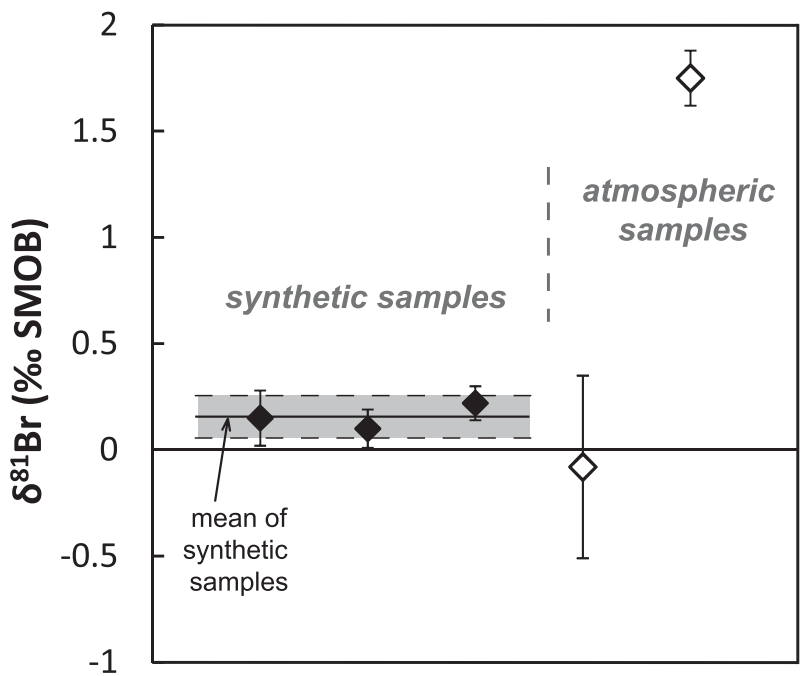

FIG. 4. Comparison of $\delta^{81} \mathrm{Br}$ in synthetic and atmospheric samples. The gray range indicates the uncertainty for $\mathrm{Br}$ isotope measurements caused by the complete sampling system (as determined using the synthetic samples). The variability of the atmospheric samples is presumed to be due to atmospheric processes and/or the isotopic signatures of natural $\mathrm{CH}_{3} \mathrm{Br}$.

nitrogen to condense the volatile target gases (in this study, methyl bromide and methyl chloride) from the air actively pumped through the sampler. There are a small number of major components, and therefore setup of the system takes at most an hour-an important factor in field work. The use of efficient drying agents and $\mathrm{CO}_{2}$ removal agents makes the system resistant to clogging during prolonged sampling cycles. We have shown that the sampler traps these gases with the necessary efficiency for isotopic studies and does not induce detectable $\mathrm{Br}$ isotope fractionation on the target $\mathrm{CH}_{3} \mathrm{Br}$ compound. Although unforeseen interferences undetectable with our testing method are, of course, possible, the lack of isotope fractionation on synthetic samples gives us strong confidence that the complete system developed and described herein does not induce quantifiable bromine isotope fractionation in $\mathrm{CH}_{3} \mathrm{Br}$, with a measured $\Delta^{81} \mathrm{Br}$ after processing of standard $\mathrm{CH}_{3} \mathrm{Br}$ of only $+0.03 \%$ o \pm $0.10 \%$. This cryosampler may find use in other atmospheric sampling work for which large volumes of cryocondensable trace gases must be collected, such as in compound-specific isotope studies.

TABLE 6. The $\delta^{81} \mathrm{Br}$ of atmospheric $\mathrm{CH}_{3} \mathrm{Br}$ samples collected at Stockholm University, autumn 2011.

\begin{tabular}{lcccc}
\hline \hline & $\begin{array}{c}\text { Br collected } \\
\text { for analysis } \\
(\mathrm{ng})\end{array}$ & $\begin{array}{c}\mathrm{Br} 1 \sigma \\
(\mathrm{ng} ; n=4)\end{array}$ & $\begin{array}{c}\delta^{81} \mathrm{Br} \text { vs } \\
\text { SMOB }\end{array}$ & $\begin{array}{c}\delta^{81} \mathrm{Br} 1 \sigma \\
\text { (with error } \\
\text { propagation) }\end{array}$ \\
\hline 29 Sep 2011 & 84.4 & 10.3 & -0.08 & $0.43(n=3)$ \\
5 Oct 2011 & 67.6 & 7.6 & 1.75 & $0.13(n=2)$ \\
\hline
\end{tabular}


Acknowledgments. This project was financially supported by the Swedish Research Council (VR Contracts 311-2007-8381 and 621-2006-5382). Author ÖG acknowledges support as an Academy Research Fellow at the Swedish Royal Academy of Sciences through a grant from the Knut and Alice Wallenberg Foundation. We thank Leif Bäcklin for constructing and pressure testing the primary cryotraps. This study was supported by the Delta Facility for Compound-Specific Isotope Analysis of the Faculty of Science, Stockholm University.

\section{REFERENCES}

Aeppli, C., H. Holmstrand, P. Andersson, and Ö. Gustafsson, 2010: Direct compound-specific stable chlorine isotope analysis of organic compounds with quadrupole GC/MS using standard isotope bracketing. Anal. Chem., 82, 420-426.

—, D. Bastviken, P. Andersson, and Ö. Gustafsson, 2013: Chlorine isotope effects and composition of naturally produced organochlorines from chloroperoxidases, flavin-dependent halogenases, and in forest soil. Environ. Sci. Technol., 47, 68676871.

Andreae, M. O., and Coauthors, 1996: Methyl halide emissions from savanna fires in southern Africa. J. Geophys. Res., 101, 23 603-23613.

Bahlmann, E., I. Weinberg, R. Seifert, C. Tubbesing, and W. Michaelis, 2011: A high volume sampling system for isotope determination of volatile halocarbons and hydrocarbons. Atmos. Meas. Tech., 4, 2073-2086.

Bill, M., R. C. Rhew, R. F. Weiss, and A. H. Goldstein, 2002: Carbon isotope ratios of methyl bromide and methyl chloride emitted from a coastal salt marsh. Geophys. Res. Lett., 29, doi:10.1029/2001GL012946.

— M. E. Conrad, and A. H. Goldstein, 2004: Stable carbon isotope composition of atmospheric methyl bromide. Geophys. Res. Lett., 31, L04109, doi:10.1029/2003GL018639.

Borrmann, S., S. Solomon, L. Avallone, D. Toohey, and D. Baumgardner, 1997: On the occurrence of $\mathrm{ClO}$ in cirrus clouds and volcanic aerosol in the tropopause region. Geophys. Res. Lett., 24, 2011-2014.

Brenninkmeijer, C. A. M., C. Janssen, J. Kaiser, T. Rockmann, T. S. Rhee, and S. S. Assonov, 2003: Isotope effects in the chemistry of atmospheric trace compounds. Chem. Rev., 103, $5125-5161$.

Butler, J. H., 2000: Atmospheric chemistry: Better budgets for methyl halides? Nature, 403, 260-261.

Carrizo, D., M. Unger, H. Holmstrand, P. Andersson, Ö. Gustafsson, S. P. Sylva, and C. M. Reddy, 2011: Compound-specific bromine isotope compositions of one natural and six industrially synthesised organobromine substances. Environ. Chem., $\mathbf{8}, 127-132$.

Coplen, T. B., 2011: Guidelines and recommended terms for expression of stable-isotope-ratio and gas-ratio measurement results. Rapid Commun. Mass Spectrom., 25, 2538-2560.

Dessens, O., G. Zeng, N. Warwick, and J. Pyle, 2009: Short-lived bromine compounds in the lower stratosphere; impact of climate change on ozone. Atmos. Sci. Lett., 10, 201-206.

Eggenkamp, H. G. M., and M. L. Coleman, 2000: Rediscovery of classical methods and their application to the measurement of stable bromine isotopes in natural samples. Chem. Geol., 167, 393-402.
Harper, D. B., 1985: Halomethane from halide ion-A highly efficient fungal conversion of environmental significance. Nature, 315, 55-57.

Hoefs, J., 2009: Stable Isotope Geochemistry. 6th ed. SpringerVerlag, $285 \mathrm{pp}$.

Holmstrand, H., M. Unger, D. Carrizo, P. Andersson, and Ö. Gustafsson, 2010: Compound-specific bromine isotope analysis of brominated diphenyl ethers using gas chromatography multiple collector/inductively coupled plasma mass spectrometry. Rapid Commun. Mass Spectrom., 24, 2135-2142.

Horst, A., H. Holmstrand, P. Andersson, A. Andersson, D. Carrizo, B. F. Thornton, and Ö. Gustafsson, 2011: Compound-specific bromine isotope analysis of methyl bromide using gas chromatography hyphenated with inductively coupled plasma multiplecollector mass spectrometry. Rapid Commun. Mass Spectrom., 25, 2425-2432.

Hu, L., S. A. Yvon-Lewis, Y. Liu, J. E. Salisbury, and J. E. O'Hern, 2010: Coastal emissions of methyl bromide and methyl chloride along the eastern Gulf of Mexico and the East Coast of the United States. Global Biogeochem. Cycles, 24, GB1007, doi:10.1029/2009GB003514.

Huff, A. K., S. S. Cliff, and M. H. Thiemens, 1997: Portable cryogenic collection of atmospheric nitrous oxide and carbon monoxide for high-precision isotopic analysis. Anal. Chem., 69, 4267-4270.

Kaufmann, R., A. Long, H. Bentley, and S. Davis, 1984: Natural chlorine isotope variations. Nature, 309, 338-340.

Keppler, F., R. M. Kalin, D. B. Harper, W. C. McRoberts, and J. T. G. Hamilton, 2004: Carbon isotope anomaly in the major plant C-1 pool and its global biogeochemical implications. Biogeosciences, 1, 123-131.

— , D. B. Harper, T. Rockmann, R. M. Moore, and J. T. G. Hamilton, 2005: New insight into the atmospheric chloromethane budget gained using stable carbon isotope ratios. Atmos. Chem. Phys., 5, 2403-2411.

Khan, M. A. H., R. C. Rhew, M. E. Whelan, K. Zhou, and S. Deverel, 2011: Methyl halide and chloroform emissions from a subsiding Sacramento-San Joaquin Delta island converted to rice fields. Atmos. Environ., 45, 977-985.

_ M. E. Whelan, and R. C. Rhew, 2012: Effects of temperature and soil moisture on methyl halide and chloroform fluxes from drained peatland pasture soils. J. Environ. Monit., 14, 241-249.

King, D. B., J. H. Butler, S. A. Montzka, S. A. Yvon-Lewis, and J. W. Elkins, 2000: Implications of methyl bromide supersaturations in the temperate North Atlantic Ocean. J. Geophys. Res., 105, 19763-19769.

Kurylo, M. J., and Coauthors, 1998: Short-lived ozone-related compounds. Scientific assessment of ozone depletion: 1998, World Meteorological Organization Global Ozone Research and Monitoring Project Rep. 44, 2.1-2.56.

Laturnus, F., 2001: Marine macroalgae in polar regions as natural sources for volatile organohalogens. Environ. Sci. Pollut. Res., 8, 103-108.

— , F. C. Adams, and C. Wiencke, 1998: Methyl halides from Antarctic macroalgae. Geophys. Res. Lett., 25, 773-776.

Law, K. S., and Coauthors, 2007: Halogenated very short-lived substances. Scientific assessment of ozone depletion: 2006, World Meteorological Organization Global Ozone Research and Monitoring Project Rep. 50, 2.1-2.57.

Lu, X. L., G. P. Yang, G. S. Song, and L. Zhang, 2010: Distributions and fluxes of methyl chloride and methyl bromide in the East China Sea and the southern Yellow Sea in autumn. Mar. Chem., 118, 75-84. 
Manley, S. L., and M. N. Dastoor, 1987: Methyl halide $\left(\mathrm{CH}_{3} \mathrm{X}\right)$ production from the giant kelp, Macrocystis, and estimates of global $\mathrm{CH}_{3} \mathrm{X}$ production by kelp. Limnol. Oceanogr., 32, 709715 .

McCauley, S. E., A. H. Goldstein, and D. J. DePaolo, 1999: An isotopic approach for understanding the $\mathrm{CH} 3 \mathrm{Br}$ budget of the atmosphere. Proc. Natl. Acad. Sci. USA, 96, $10006-$ 10009.

Mead, M. I., M. A. H. Khan, G. Nickless, B. R. Greally, D. Tainton, T. Pitman, and D. E. Shallcross, 2008: Leaf cutter ants: A possible missing source of biogenic halocarbons. Environ. Chem., 5, 5-10.

Miller, L. G., R. M. Kalin, S. E. McCauley, J. T. G. Hamilton, D. B. Harper, D. B. Millet, R. S. Oremland, and A. H. Goldstein, 2001: Large carbon isotope fractionation associated with oxidation of methyl halides by methylotrophic bacteria. Proc. Natl. Acad. Sci. USA, 98, 5833-5837.

Montzka, S. A., and Coauthors, 2011: Ozone-depleting substances (ODSs) and related chemicals. Scientific assessment of ozone depletion: 2010, World Meteorological Organization Global Ozone Research and Monitoring Project Rep. 52, 1-1.108.

Numata, M., N. Nakamura, H. Koshikawa, and Y. Terashima, 2002: Chlorine isotope fractionation during reductive dechlorination of chlorinated ethenes by anaerobic bacteria. Environ. Sci. Technol., 36, 4389-4394.

Paneth, P., 2003: Chlorine kinetic isotope effects on enzymatic dehalogenations. Acc. Chem. Res., 36, 120-126.

Redeker, K. R., J. Andrews, F. Fisher, R. Sass, and R. J. Cicerone, 2002: Interfield and intrafield variability of methyl halide emissions from rice paddies. Global Biogeochem. Cycles, 16, 1125, doi:10.1029/2002GB001874.

Rhew, R. C., and O. Mazéas, 2010: Gross production exceeds gross consumption of methyl halides in northern California salt marshes. Geophys. Res. Lett., 37, L18813, doi:10.1029/ 2010 GL044341.

_ _ B. R. Miller, and R. F. Weiss, 2000: Natural methyl bromide and methyl chloride emissions from coastal salt marshes. Nature, 403, 292-295.

— , Y. A. Teh, and T. Abel, 2007: Methyl halide and methane fluxes in the northern Alaskan coastal tundra. J. Geophys. Res., 112, G02009, doi:10.1029/2006JG000314.

Rudolph, J., D. C. Lowe, R. J. Martin, and T. S. Clarkson, 1997: A novel method for compound specific determination of $\delta^{13} \mathrm{C}$ in volatile organic compounds at ppt levels in ambient air. Geophys. Res. Lett., 24, 659-662.

Saito, T., and Y. Yokouchi, 2008: Stable carbon isotope ratio of methyl chloride emitted from glasshouse-grown tropical plants and its implication for the global methyl chloride budget. Geophys. Res. Lett., 35, L08807, doi:10.1029/2007GL032736.

— - _ Y. Kosugi, M. Tani, E. Philip, and T. Okuda, 2008: Methyl chloride and isoprene emissions from tropical rain forest in Southeast Asia. Geophys. Res. Lett., 35, L19812, doi:10.1029/2008GL035241.

Salawitch, R. J., D. K. Weisenstein, L. J. Kovalenko, C. E. Sioris, P. O. Wennberg, K. Chance, M. K. W. Ko, and C. A. McLinden, 2005: Sensitivity of ozone to bromine in the lower stratosphere. Geophys. Res. Lett., 32, L05811, doi:10.1029/2004GL021504.
Schauffler, S. M., L. E. Heidt, W. H. Pollock, T. M. Gilpin, J. F. Vedder, S. Solomon, R. A. Lueb, and E. L. Atlas, 1993: Measurements of halogenated organic compounds near the tropical tropopause. Geophys. Res. Lett., 20, 2567-2570. , and Coauthors, 2003: Chlorine budget and partitioning during the Stratospheric Aerosol and Gas Experiment (SAGE) III Ozone Loss and Validation Experiment (SOLVE). J. Geophys. Res., 108, 4173, doi:10.1029/2001JD002040.

Shouakar-Stash, O., S. V. Alexeev, S. K. Frape, L. P. Alexeeva, and R. J. Drimmie, 2007: Geochemistry and stable isotopic signatures, including chlorine and bromine isotopes, of the deep groundwaters of the Siberian platform, Russia. Appl. Geochem., 22, 589-605.

Simmonds, P. G., and Coauthors, 2004: AGAGE observations of methyl bromide and methyl chloride at Mace Head, Ireland, and Cape Grim, Tasmania, 1998-2001. J. Atmos. Chem., 47, 243-269.

Singh, H. B., L. J. Salas, and R. E. Stiles, 1983: Methyl halides in and over the eastern Pacific $\left(40^{\circ} \mathrm{N}-32^{\circ} \mathrm{S}\right)$. J. Geophys. Res., 88, 3684-3690.

Sinnhuber, B.-M., and Coauthors, 2005: Global observations of stratospheric bromine monoxide from SCIAMACHY. Geophys. Res. Lett., 32, L20810, 10.1029/2005GL023839.

Sive, B. C., and Coauthors, 2005: Development of a cryogen-free concentration system for measurements of volatile organic compounds. Anal. Chem., 77, 6989-6998.

Sylva, S. P., L. Ball, R. K. Nelson, and C. M. Reddy, 2007: Compoundspecific $81 \mathrm{Br} / 79 \mathrm{Br}$ analysis by capillary gas chromatography/ multicollector inductively coupled plasma mass spectrometry. Rapid Commun. Mass Spectrom., 21, 3301-3305.

Teh, Y. A., O. Mazeas, A. R. Atwood, T. Abel, and R. C. Rhew, 2009: Hydrologic regulation of gross methyl chloride and methyl bromide uptake from Alaskan Arctic tundra. Global Change Biol., 15, 330-345.

Thornton, B. F., D. W. Toohey, L. M. Avallone, H. Harder, M. Martinez, J. B. Simpas, W. H. Brune, and M. A. Avery, 2003: In situ observations of $\mathrm{ClO}$ near the winter polar tropopause. J. Geophys. Res., 108, 8333, doi:10.1029/2002JD002839.

_ , and Coauthors, 2007: Chlorine activation near the midlatitude tropopause. J. Geophys. Res., 112, D18306, doi:10.1029/ 2006JD007640.

UNEP, 2012: Handbook for the Montreal Protocol on Substances that Deplete the Ozone Layer. 9th ed. United Nations Environment Programme, 708 pp.

Varner, R. K., P. M. Crill, and R. W. Talbot, 1999: Wetlands: A potentially significant source of atmospheric methyl bromide and methyl chloride. Geophys. Res. Lett., 26, 2433-2435.

von Hobe, M., and Coauthors, 2011: Evidence for heterogeneous chlorine activation in the tropical UTLS. Atmos. Chem. Phys., 11, 241-256.

Williams, J., N. Y. Wang, R. J. Cicerone, K. Yagi, M. Kurihara, and F. Terada, 1999: Atmospheric methyl halides and dimethyl sulfide from cattle. Global Biogeochem. Cycles, 13, 485-491.

Yvon-Lewis, S. A., E. S. Saltzman, and S. A. Montzka, 2009: Recent trends in atmospheric methyl bromide: Analysis of post-Montreal Protocol variability. Atmos. Chem. Phys., 9, $5963-5974$. 